\title{
ANTHROPOMETRIC PREDICTORS OF BLOOD PRESSURE IN WOMEN BETWEEN THE AGES 26-45 YEARS
}

\author{
DZINTRA KAŽOKA \\ Institute of Anatomy and Anthropology, Riga Stradiņš University, Latvia
}

\begin{abstract}
The study of 199 (26 to 45 years) women of Latvia was undertaken to study the anthropometric predictors of blood pressure between age groups. The data were collected in the years 2001-2005. The women were divided into two agegroups: I (26-35 years) and II (36-45 years) for making even sample analysis. Anthropometric variables of each woman including height, weight, waist and hip circumferences (WC, HC), and blood pressure (BP) were measured. Mean arterial blood pressure (MBP), waist-to-hip ratio (WHR), waist-to-height ratio (WHtR) and body mass index (BMI) were also calculated through standard equation. The relationships between blood pressure and different anthropometric variables were determined in both age groups. The mean age of the participants was $35.18 \pm 2.85$. The mean \pm SD systolic blood pressures were $124.25 \pm 12.81$ and $131.52 \pm 17.04 \mathrm{mmHg}$ while the mean diastolic blood pressures were $82.78 \pm 9.78$ and $88.71 \pm 12.44 \mathrm{mmHg}$ in both age groups. The mean values of systolic and diastolic blood pressures increased with age. In this study anthropometric measurements such as weight, waist and hip circumferences (WC, HC), waist-to-height ratio (WHtR) and body mass index (BMI) indicated a strong positive relation with blood pressure in both age groups. Waist-to-hip ratio (WHR) was not a significant predictor for systolic and diastolic blood pressures of women at the age of 26-35 years. According to this study, selected anthropometric measures were significant predictors of systolic and diastolic blood pressures. Therefore, it is important that early measurements of blood pressure, weight, waist and hip circumferences (WC, HC), and some indices become a routine in health services in order to prevent conditions or risk factors of different diseases.
\end{abstract}

Keywords: adult women, age variations, blood pressure, predictors, anthropometry 


\section{INTRODUCTION}

A number of studies demonstrate that the European countries have significant problems with cardiovascular diseases (CVD) and a high prevalence of their risk factors resulting in the high mortality rate. Latvia is not an exception. Hypertension is one of the most common and important risk factors for cardiovascular diseases [7]. Several studies from different populations have reported significant association between different anthropometric indicators and blood pressure $[6,10]$.

Different anthropometric measurements such as height, weight, waist and hip circumferences (WC, HP), waist hip ratio (WHR), waist-to-hip ratio (WHtR) and body mass index (BMI) are used at present as risk factors for a cardiovascular disease. Many prospective and cross-sectional studies have used different anthropometric measures to understand the relationship between these measures and blood pressure. High blood pressure (BP), which is indirectly identified through anthropometric indicators, may be an efficient strategy for the detection and control of obesity and hypertension.

Since it is essential to determinate anthropometric indices, which are more associated with changes of blood pressure, the present study was carried out to evaluate these anthropometric predictors of systolic (SBP) and diastolic (DBP) blood pressure levels and the status in women between the ages $26-45$ years in Latvia.

\section{MATERIAL AND METHODS}

For anthropometric data, the women, who voluntarily agreed to participate in the study, have been incorporated in the sample (199 females). The programme included several procedures and collected many different variables of data. Anthropometric data have been collected from adult women. All the anthropometric measurements were made by trained investigators according to the methodical recommendations by R. Martin and K. Saller [12, 13], using the Swiss company's "Siber-Hegner and Co" anthropometric instruments. Anthropometric data include height, weight, waist and hip circumferences. Standing height was measured using Anthropometer and weight was measured on a digital scale. Height was measured to the nearest 0.1 centimeter $(\mathrm{cm})$. For the evaluation of body weight a portable scale with a $0.1 \mathrm{~kg}$ precision was used. The circumferences were measured using a measuring tape. Waist circumference was measured in centimeters midway between the lower costal margin and iliac crest during the end-expiratory phase. Hip circumference was measured in centimeters at the level of the greater trochanters. All 
the measurements were recorded to the nearest centimeter. Waist-to-hip ratio (WHR) was defined as the waist circumference divided by the hip circumference, while the waist-to-height ratio (WHtR) was defined as the waist circumference divided by the height in centimeters [16]. The body mass index (BMI) was computed using the following standard equation: $\mathrm{BMI}\left(\mathrm{kg} / \mathrm{m}^{2}\right)=$ weight $(\mathrm{kg}) /$ height $\left(\mathrm{m}^{2}\right)[21]$.

The researcher and the trained staff measured blood pressure. The respondent was advised to sit quietly and rest for 5 minutes with their legs uncrossed and their right arm free of clothing. Then, the right arm was placed on the table with the palm facing upwards. Blood pressure was measured at the level of the heart after relaxing for 5 minutes while sitting in the vertical position, using a digital and validated blood pressure device. The physiometric variables included the measurement of systolic blood pressure (SBP) and diastolic blood pressure (DBP). The mean arterial blood pressure (MBP) was calculated for each of the two readings taken for SBP and DBP by using the formula [17]: $\mathrm{MBP}=\mathrm{DBP}+(\mathrm{SBP}-\mathrm{DBP}) / 3$.

All the women were categorized according to the age into the following groups: 26-35 years (group I) and 36-45 years (group II).

Statistical analysis was performed using IBM SPSS Statistics (version 20.0) and descriptive variables such as mean, median, standard deviations were used. The independent sample t-test was used to establish differences between groups and systolic and diastolic blood pressure. The values $\mathrm{p}<0.001, \mathrm{p}<0.01$ and $\mathrm{p}<0.05$ were considered significant.

\section{RESULTS}

The mean age of the participants was $35.18 \pm 2.85$. Age specific descriptive statistics for blood pressure measurements and other anthropometric variables of females are presented in Tables 1 and 2.

Consistent increase of the mean values of SBP and DBP with the increase of age has been observed. The mean \pm SD systolic blood pressures were $124.25 \pm 12.81$ and $131.52 \pm 17.04 \mathrm{mmHg}$ while the mean diastolic blood pressures were $82.78 \pm 9.78$ and $88.71 \pm 12.44 \mathrm{mmHg}$ in both age groups. The increasing age trend has also been noticed in other anthropometric variables. The mean of weight, WC, HC and BMI increased significantly from $64.31 \mathrm{~kg}$, $73.16 \mathrm{~cm}, 96.55 \mathrm{~cm}$ and $23.59 \mathrm{~kg} / \mathrm{m}^{2}$ to $70.40 \mathrm{~kg}, 79.16 \mathrm{~cm}, 101.72 \mathrm{~cm}$ and $26.25 \mathrm{~kg} / \mathrm{m}^{2}$ respectively between the ages of $26-45$ years. There were differences between the mean values of WHR (0.76 and 0.78) and WHtR (0.44 and $0.48)$ in both age groups. 
Table 1. Age related variables of anthropometric measurements among women in Latvia $(\mathrm{m} \pm \mathrm{SD})$

\begin{tabular}{lcc}
\hline & \multicolumn{2}{c}{ Age groups (years) } \\
\cline { 2 - 3 } & $\begin{array}{c}26-35 \\
(\mathrm{n}=94)\end{array}$ & $\begin{array}{c}36-45 \\
(\mathrm{n}=105)\end{array}$ \\
\hline body height $(\mathrm{cm})$ & $165.06 \pm 6.35$ & $163.86 \pm 6.50$ \\
\hline body weight $(\mathrm{kg})$ & $64.31 \pm 12.34$ & $70.40 \pm 14.31$ \\
\hline $\mathrm{WC}(\mathrm{cm})$ & $73.16 \pm 9.72$ & $79.16 \pm 12.84$ \\
\hline $\mathrm{HC}(\mathrm{cm})$ & $96.55 \pm 10.04$ & $101.72 \pm 11.14$ \\
\hline BMI $\left(\mathrm{kg} / \mathrm{m}^{2}\right)$ & $23.59 \pm 4.27$ & $26.25 \pm 5.35$ \\
\hline $\mathrm{WHR}$ & $0.76 \pm 0.05$ & $0.78 \pm 0.06$ \\
\hline $\mathrm{WH} \mathrm{tR}$ & $0.44 \pm 0.06$ & $0.48 \pm 0.08$ \\
\hline
\end{tabular}

n - number of women; $m$ - mean; SD - standard deviation; WC - waist circumference; HC - hip circumference; BMI - body mass index; WHR - waist-to-hip ratio; WHtR - waist-to-height ratio

Table 2. Age related variables of blood pressures among women in Latvia $(\mathrm{m} \pm \mathrm{SD})$

\begin{tabular}{ccc}
\hline & \multicolumn{2}{c}{ Age groups (years) } \\
\cline { 2 - 3 } & $\begin{array}{c}26-35 \\
(\mathbf{n}=\mathbf{9 4})\end{array}$ & $\begin{array}{c}36-45 \\
(\mathbf{n}=105)\end{array}$ \\
\hline $\mathrm{SBP}(\mathrm{mm} / \mathrm{Hg})$ & $124.25 \pm 12.81$ & $131.52 \pm 17.04$ \\
\hline $\mathrm{DBP}(\mathrm{mm} / \mathrm{Hg})$ & $82.78 \pm 9.78$ & $88.71 \pm 12.44$ \\
\hline $\mathrm{MBP}(\mathrm{mm} / \mathrm{Hg})$ & $96.61 \pm 9.96$ & $102.98 \pm 13.29$ \\
\hline
\end{tabular}

$\mathrm{n}$ - number of women; $\mathrm{m}$ - mean; SD - standard deviation; SBP - systolic blood pressure; DBP - diastolic blood pressure; MBP - mean arterial blood pressure

The age-dependent description of blood pressure in relation to age groups among adult women is shown in Table 3.

The correlation coefficients of systolic and diastolic blood pressure in relation to some variables of anthropometrical measurements among adult women are shown in Table 4. The weight, waist and hip circumferences (WC, $\mathrm{HC}$ ), waist-to-height ratio (WHtR) and body mass index (BMI) were found significantly correlated with SBP and DBP in both age groups. 
Table 3. Age-dependent description of blood pressure in relation to age groups among adult women in Latvia

\begin{tabular}{|c|c|c|c|c|c|c|c|}
\hline \multirow{2}{*}{$\begin{array}{c}\text { Age } \\
\text { groups } \\
\text { (years) }\end{array}$} & \multirow{2}{*}{$\begin{array}{c}\text { Blood } \\
\text { pressure }\end{array}$} & \multirow[t]{2}{*}{$\mathrm{n}$} & \multirow[t]{2}{*}{$\mathrm{m}$} & \multirow[t]{2}{*}{ SD } & \multicolumn{2}{|c|}{$\begin{array}{c}95 \% \text { confidence } \\
\text { interval }\end{array}$} & \multirow{2}{*}{$P$ value } \\
\hline & & & & & low & high & \\
\hline \multirow{2}{*}{$26-35$} & SBP & \multirow{2}{*}{94} & 124.25 & 12.81 & 121.61 & 126.89 & \multirow{2}{*}{$<0.001$} \\
\hline & DBP & & 82.78 & 9.78 & 80.77 & 84.80 & \\
\hline \multirow{2}{*}{$36-45$} & SBP & \multirow{2}{*}{105} & 131.52 & 17.04 & 128.23 & 134.82 & \multirow{2}{*}{$<0.001$} \\
\hline & DBP & & 88.71 & 12.44 & 86.31 & 91.12 & \\
\hline
\end{tabular}

$\mathrm{n}$ - number of women; $\mathrm{m}$ - mean; SD - standard deviation; SBP - systolic blood pressure; DBP - diastolic blood pressure

Table 4. The correlation coefficients of systolic and diastolic blood pressure in relation to some variables of anthropometric measurements among adult women in Latvia

\begin{tabular}{|c|c|c|c|c|c|c|c|c|}
\hline \multirow{4}{*}{ Variables } & \multicolumn{4}{|c|}{ SBP } & \multicolumn{4}{|c|}{ DBP } \\
\hline & \multicolumn{4}{|c|}{ Age groups (years) } & \multicolumn{4}{|c|}{ Age groups (years) } \\
\hline & \multicolumn{2}{|c|}{$\begin{array}{l}26-35 \\
(n=94)\end{array}$} & \multicolumn{2}{|c|}{$\begin{array}{c}36-45 \\
(n=105)\end{array}$} & \multicolumn{2}{|c|}{$\begin{array}{l}26-35 \\
(n=94)\end{array}$} & \multicolumn{2}{|c|}{$\begin{array}{c}36-45 \\
(n=105)\end{array}$} \\
\hline & $r$ & $p$ & $r$ & $\mathrm{p}$ & $r$ & $\mathrm{p}$ & $r$ & $p$ \\
\hline body weight & 0.378 & $\mathrm{p}<0.01$ & 0.382 & $\mathrm{p}<0.01$ & 0.311 & $\mathrm{p}<0.01$ & 0.351 & $p<0.01$ \\
\hline WC & 0.425 & $\mathrm{p}<0.01$ & 0.441 & $\mathrm{p}<0.01$ & 0.277 & $p<0.01$ & 0.411 & $p<0.01$ \\
\hline $\mathrm{HC}$ & 0.426 & $\mathrm{p}<0.01$ & 0.413 & $\mathrm{p}<0.01$ & 0.353 & $p<0.01$ & 0.398 & $p<0.01$ \\
\hline BMI & 0.378 & $\mathrm{p}<0.01$ & 0.445 & $\mathrm{p}<0.01$ & 0.304 & $\mathrm{p}<0.01$ & 0.427 & $\mathrm{p}<0.01$ \\
\hline WHR & 0.169 & $p=0.106$ & 0.314 & $\mathrm{p}<0.01$ & 0.003 & $p=0.974$ & 0.254 & $p<0.01$ \\
\hline WHtR & 0.394 & $\mathrm{p}<0.01$ & 0.461 & $\mathrm{p}<0.01$ & 0.249 & $\mathrm{p}<0.05$ & 0.440 & $\mathrm{p}<0.01$ \\
\hline
\end{tabular}

SBP - systolic blood pressure; DBP - diastolic blood pressure; WC - waist circumference; HC - hip circumference; BMI - body mass; WHR - waist-to-hip ratio; WHtR - waist-to-height ratio

At the age of 26-35 among the measurements analyzed, $\mathrm{HC}$ showed the strongest correlation with SBP levels $(r=0.426, p<0.01)$, followed by WC $(\mathrm{r}=0.425, \mathrm{p}<0.01)$ and WHtR $(\mathrm{r}=0.394, \mathrm{p}<0.01)$. The strongest correlation with DBP levels showed HC $(r=0.353, p<0.01)$, weight $(r=0.311, p<0.01)$ and BMI $(\mathrm{r}=0.304, \mathrm{p}<0.01)$. In this group of women waist-to-hip ratio (WHR) was not significantly correlated with systolic and diastolic blood pressures. 
In the age group 36-45 of women the strongest correlation with SBP and DBP levels showed WHtR $(\mathrm{r}=0.461, \mathrm{p}<0.01$ and $\mathrm{r}=0.440, \mathrm{p}<0.01)$, followed by BMI $(\mathrm{r}=0.445, \mathrm{p}<0.01$ and $\mathrm{r}=0.427, \mathrm{p}<0.01)$ and $\mathrm{WC}(\mathrm{r}=0.441, \mathrm{p}<0.01$ and $\mathrm{r}=0.411, \mathrm{p}<0.01)$.

\section{DISCUSSION}

Based on the results of most studies, the importance of waist and hip circumferences (WC, HC), waist-to-hip ratio (WHR), waist-to-height ratio (WHtR) and body mass index (BMI) have been recognized for estimating cardiovascular disease risk factors, particularly due to their positive association with blood pressure [20]. A great number of studies have shown that cardiovascular morbidity and mortality are strongly correlated with the increased diastolic and systolic blood pressure $[5,15]$.

In accordance with other reports, this study showed a significant association between anthropometric measures and blood pressure. Waist and hip circumferences (WC, HC) were found to be a significant predictor of both SBP and DBP levels. The waist circumference (WC) describes the fat located in the central region of the body. This is in agreement with the studies which showed an important relationship specially between waist circumference (WC) and the probability of emerging cardiovascular events $[1,18]$.

The waist-to-hip ratio (WHR) is one of the most commonly used anthropometric measures to indicate a central obesity pattern and an increased risk of cardiovascular disease [3]. The finding of the present study indicated that WHR was not significantly correlated with the blood pressures level of women at the age of 26-35 years. Some studies found that WHR was significantly associated with hypertension and was considered to be an important predictor, but there can be variations in such results [8]. However, methodological differences, the number of measurements taken and the different reference criteria are the main causes of high variability in the level of blood pressure among the investigations.

Body mass index (BMI) predicts the overall fat and several studies have found that BMI is a significant predictor of increasing of blood pressure and hypertension, but other studies do not agree $[9,19]$. BMI is a most commonly used measure of overweight and obesity $[6,21]$ and has been found to be an important risk factor for CVD [10]. In the present study also BMI showed strong correlation of with blood pressure.

The waist-to-height ratio (WHtR) considers the proportion of central fat by the individual's height. In this investigation WHtR was found to be the 
important predictor of the blood pressure level and this is in agreement with several other studies [4]. Some investigations have concluded that, compared with BMI, WHtR was more strongly associated with cardiovascular risk factors $[11,14]$.

In this study was found significant positive correlations between some anthropometric parameters and systolic and diastolic blood pressure were found. Many investigators have earlier reported the significant positive correlation of BMI with systolic and diastolic blood pressure [2]. The findings of the present study are important to emphasize the need for an early diagnosis of some risk factors of blood pressure increasing and the designing of proper preventive measures in the future.

\section{ABBREVIATIONS}

Blood pressure (BP); Systolic blood pressure (SBP); Diastolic blood pressure (DBP); Mean blood pressure (MBP); Waist circumference (WC); Hip circumference (HC); Waist-to-hip ratio (WHR); Waist-to-height ratio (WHtR); Body mass index (BMI); Standard deviation (SD); Cardiovascular diseases (CVD)

\section{ACKNOWLEDGEMENTS}

This study was undertaken as a part of investigation "Appreciation of biological status of women in Latvia". It was funded by the European Union Structural Funds for Scientific Research. In addition, acknowledgements are given to the medical nurses of the anthropology unit for helping during anthropometric measurements of women and also the following institutions: Riga Stradiņš University, the Institute of Anatomy and Anthropology, the Department of Anthropology and Physics Department.

\section{REFERENCES}

1. Ashwell M., Gunn P., Gibson S. (2012). Waist-to-height ratio is a better screening tool than waist circumference and BMI for adult cardiometabolic risk factors: systematic review and meta-analysis. Obes Rev, 13, 3, 275-286.

2. Beck K., Silva Lopes A., Pitanga F. (2011). Anthropometric indicators as predictors of high blood pressure in adolescents. Arq Bras Cardiol, 96, 2, 126-133.

3. Browning L.M., Hsieh S.D., Ashwell M. (2010). A systematic review of waistto-height ratio as a screening tool for the prediction of cardiovascular disease and diabetes: 0.5 could be a suitable global boundary value. Nutr Res Rev, 23, $2,247-269$. 
4. Cai L., Liu A., Zhang Y., Wang P. (2013). Waist-to-Height Ratio and Cardiovascular Risk Factors among Chinese Adults in Beijing. Public library of sci, 8, $7-8$.

5. Chen X., Zhang Z.X., George L.K., Wang Z.S., Fan Z.J., Xu T., Zhou X.L., Han S.M., Wen H.B., Zeng Y. (2012). Birth measurements, family history and environmental factors associated with laterlife hypertensive status. Am J Hypertens, 25, 464-471.

6. Dhall M., Shilpi G., Monika B., Pankhuri S., Satwanti K. (2011). Effectiveness of various anthropometric indices in prediction of cardiovascular risk among adult Jains. The Open Anthropology J, 4, 33-39.

7. Erglis A., Dzerve V., Pohomova-Strautina J., Narbute I., Pahomova-Strautina J., Narbute I., Jegere S., Mintale I., Ligere R., Apinis P., Lejnieks A., Misina D., Rozenbergs A. (2012). A Population-Based cross-Sectional study of Cardiovascular risk Factor in Latvia. Medicina (Kaunas), 48, 6, 311-316.

8. Flores-Huerta S., Klünder-Klünder M., Reyes de la Cruz L., Santos J.I. (2009). Increase in body mass index and waist circumference is associated with high blood pressure in children and adolescents in Mexico city. Arch Med Res, 40, 3, 208-215.

9. Kabalin M., Kolarić B., Marchesi V.V., Pereza N., Ostojić S., Rukavina T., Kapović M. (2012). Body mass index, waist circumference and waist-to-hip ratio: which anthropometric indicator is better predictor for the hypertension development in women population of the island Cres. Coll Antropol, 36, 2, 363-368.

10. Knowles K.M., Paiva L.L., Sanchez S.E., Revilla L., Lopez T., Yasuda M.B., Yanez N.D., Gelaye B., Williams M.A. (2011). Waist Circumference, BodyMass Index, and Other Measures of Adiposity in Predicting Cardiovascular Disease Risk Factors among Peruvian Adults. Int. J. Hypertens, 93, 1-10.

11. Kuba V.M., Claudio L., Durval D. (2013) Is waist-to-height ratio a useful indicator of cardio-metabolic risk in 6-10-year-old children? Paediatrics, 13, 1-6.

12. Martin R. Lehrbuch der Anthropologie. I und II Bd. Jena, 1928.

13. Martin R., Saller K. Lehrbuch der Anthropologie. Stuttgart, Fischer, Bd. I., 1957.

14. Nambiar S., Hughes I., Davies P.S. (2010). Developing waist-to-height ratio cut-offs to define overweight and obesity in children and adolescents. Public Health Nutr, 13, 1566-1574.

15. Palacios C., Perez C.M., Guzman M., Ortiz A.P., Ayala A., Suarez E. (2011). Association between adiposity indices and cardiometabolic risk factors among adults living in Puerto Rico. Public health nutr, 10, 1714-1723.

16. Park S.H., Choi S.J., Lee K.S., Park H.Y. (2009). Waist circumference and waistto height ratio as predictors of cardiovascular disease risk in Korean adults. Circ J, 73, 9, 1643-1650. 
17. Perusse L., Rice T., Bouchard C., Vogler G.P., Rao D.C. (1989). Cardiovascular risk factors in a French-Canadian population: resolution of genetic and familial environment effects on blood pressure by using extensive information on environment correlates. Am J Hum Genet, 45, 240-252.

18. Stevens J., Katz E.G., Huxley R.R. (2010). Associations between gender, age and waist circumference. Eur J Clin Nutr, 64, 1, 6-15.

19. Uhernik A.I., Milanović S.M. (2009). Anthropometric indices of obesity and hypertension in different age and gender groups of Croatian population. Coll Antropol, 33, 1, 75-80.

20. Vrdoljak D., Bergman Marković B., Kranjčević K., Ivezić Lalić D., Vučak J., Katić M. (2012). How well do anthropometric indices correlate with cardiovascular risk factors? A cross-sectional study. Croati Med Sci Monit, 18, 2, 6-11.

21. WHO Expert Committee (1995). The Use and Interpretation of Anthropometry. WHO Technical Report Series no. 854. Geneva: WHO.

Address for correspondence:

Dzintra Kažoka

Institute of Anatomy and Anthropology

Riga Stradiņš University

Kronvalda blv. 9, Riga, Latvia, LV-1010

E-mail: Dzintra.Kazoka@rsu.lv 